\title{
Article
}

\section{Adsorption Behavior of Divalent Metal Ions with $\beta$-diketone Retained on Octadecyl Silica Gel}

\author{
Masamitsu Iiyama \\ Functional Product Div., Nomura Micro Science Co., Ltd., 2-4-37, Okada, Atsugi, Kanagawa, 243-0021, Japan \\ Hisao Kokusen \\ Department of Essential Education, School of Pharmacy, Hokkaido Pharmaceutical University, \\ 7-1 Katsuraoka-cho, Otaru, Hokkaido 047-0264, Japan \\ Shigekazu Tsurubou \\ Department of Chemistry, School of Dentistry, Asahi University, \\ 1851 Hozumi, Hozumi-cho, Motosu-gun, Gifu 501-0296, Japan \\ Yu Komatsu \\ Department of Environmental Chemistry, College of Environmental Engineering and Architecture, \\ Kanazawa Institute of Technology, 7-1 Ohgigaoka, Nonoichi, Ishikawa 921-8501, Japan
}

(Manuscript submitted March 31, 2007; accepted June 25, 2007)

\begin{abstract}
This investigation looked at the separation of divalent metal ions, such as $\mathrm{Cu}(\mathrm{II}), \mathrm{Cd}(\mathrm{II})$ and $\mathrm{Pb}(\mathrm{II})$, in an aqueous solution. The adsorbents were synthesized with $\beta$-diketones, such as 4,4-trifluoro-1-(2-thienyl)-1,3-butadione (TTA) or 4,4,4-trifluoro-1-phenyl-1,3-butanedione(BFA), retained on the octadecylsilica $(\mathrm{C} 18)$. The reaction ability of these adsorbents (TTA-, BFA-C18) was evaluated by adsorption reaction behavior. It was found that the metal ions examined here were adsorbed both on TTA-C18 and BFA-C18 at $\mathrm{pH} 1.5-6.0$ and the selectivity series was found in the order $\mathrm{Cu}^{2+}>\mathrm{Pb}^{2+}>\mathrm{Cd}^{2+}$. These synthesized adsorbents have an advantage that the water-insoluble chelate reagents can be used without using organic solvents.
\end{abstract}

Key words: adsorbent, $\beta$-diketone, $\mathrm{Cu}(\mathrm{II}), \mathrm{Cd}(\mathrm{II}), \mathrm{Pb}(\mathrm{II})$

\section{Introduction}

Cadmium and lead, both of which have been reported to be terribly toxic to animals and human beings, are frequently encountered together in fine-chemical process or battery industry wastewater. A solvent extraction using $\beta$-diketone such as 4,4-trifluoro-1-(2-thienyl)-1,3-butadione (TTA : Fig.1) is known to be one of the most effective methods for removal the toxic metal ions.[1] However, separation among similar structural metal ions is difficult in a batch processing. We have developed a new solvent extraction method to efficiently remove metal ions using an octadecylsilica (C18).[2] This method showed an increase in the extraction ability of the metal ions compared with the normal solvent extraction method.[3] A system developed do not need organic solvent by retaining the $\beta$-diketone directly onto $\mathrm{C} 18$. It was reported that the synthesized material has adsorption ability of divalent transition metal ions, and the adsorption selectivity series was $\mathrm{Cu}^{2+}>\mathrm{Ni}^{2+}>\mathrm{Co}^{2+} \geq \mathrm{Zn}^{2+}>\mathrm{Mn}^{2+}$.[4] In this study, the TTA and 4,4,4-trifluoro-1-phenyl-1,3- butanedione (BFA : Fig.1) as $\beta$-diketone chelating agent were 
retained onto $\mathrm{C} 18$. They were abbreviated as TTA-C18 and BFA-C18. These adsorbents were applied to adsorb divalent toxic heavy metal ions, $\mathrm{Cu}^{2+}, \mathrm{Cd}^{2+}$ and $\mathrm{Pb}^{2+}$, from an aqueous solution. The results are reported with the quantitative analysis of adsorption behavior for the metal ions using TTA-C18 and BFA-C18.<smiles>O=C(/C=C(\O)C(F)(F)F)c1cccs1</smiles>

(TTA)<smiles>O=C(/C=C(\O)C(F)(F)F)c1ccccc1</smiles>

(BFA)

Fig. 1 Structure of 4,4,4-trifluoro-1-(2-thienyl)-1,3-butanedione (TTA) and 4,4,4-trifluoro-1-(2-phenyl)-1,3-butanedione(BFA).

\section{Experimental}

\subsection{Reagents and Apparatus}

The silica gel (Wako Pure Chemical Industries, $1-2 \mathrm{~mm}$ particle size) was crushed and sieved to a size of 0.50 - $1.0 \mathrm{~mm}$. TTA and BFA were purchased from Dojindo Laboratories. All other reagents were analytical grade. Deionized water was prepared by Milli-Q Gradient A10 (MILLIPORE) and used throughout.

An inductively coupled argon-plasma atomic emission spectrometry (ICP-AES, VARIAN VISTA-PRO) was used to determine metal ion concentration in aqueous solution. The $\mathrm{pH}$ values of aqueous solutions were measured by a $\mathrm{pH}$ meter (HORIBA F-21) equipped with a glass electrode.

\subsection{Preparation of TTA-C18 and BFA-C18}

C18 was synthesized according to a published method.[5] In order to synthesize the TTA-C18 and BFA-C18, $50 \mathrm{~cm}^{3}$ of toluene containing $0.5 \mathrm{~mol} \mathrm{dm}$ TTA or BFA was added to $10 \mathrm{~g}$ of C18. After standing for 24 hours at $277 \mathrm{~K}$, the mixed solution was filtrated, washed with deionized water and dried at room temperature under vacuum.

\subsection{Adsorption Reaction}

Aqueous solutions were prepared containing $1.0 \times 10^{-4} \mathrm{~mol} \mathrm{dm}^{-3}$ metal ions $\left(\mathrm{Cu}^{2+}, \mathrm{Cd}^{2+}\right.$ or $\left.\mathrm{Pb}^{2+}\right), 0.1 \mathrm{~mol} \mathrm{dm}^{-3}$ sodium perchlorate and $2.0 \times 10^{-2} \mathrm{~mol} \mathrm{dm}^{-3}$ of buffer agent (chloroacetic acid or acetic acid). A $20 \mathrm{~cm}^{3}$ aliquot of each solution, along with $0.3 \mathrm{~g}$ of TTA-C18 or BFA-C18, was put into a $50 \mathrm{~cm}^{3}$ stoppered glass tube. The tubes were shaken a few times each day to reach reaction equilibrium (within 36 hours) at $298 \mathrm{~K}$. After the reaction was complete, the mixed solutions were filtered. The concentration of metal ions in the aqueous solutions was determined by ICP-AES and the $\mathrm{pH}$ value was measured.

\subsection{Characterization of Material}

\section{Results and discussion}

The bonded Si-octadecyl group was confirmed by measuring FT-IR spectra of the synthesized C18. The amount of TTA or BFA retained on C18 was found to be $0.19 \pm 0.01 \mathrm{mmol} \mathrm{g}^{-1}$. (n=3) and $0.095 \pm 0.008 \mathrm{mmol} \mathrm{g}^{-1}(\mathrm{n}=4)$, respectively. These values were measured by the flask combustion method.[6] Meanwhile, silica gel that had not bonded with an octadecyl group was not able to retain $\beta$-diketone.

\subsection{Analysis of Adsorption Behavior}

Since the divalent metal ions such as $\mathrm{Cu}^{2+}, \mathrm{Cd}^{2+}$ or $\mathrm{Pb}^{2+}$ were used for this study, the reaction between TTA-C18 
or BFA-C18 and the metal ions can be expressed as

$$
\mathrm{M}_{(\mathrm{aq})}^{2+}+2 \mathrm{HR}_{(\mathrm{sol})} \stackrel{K}{\rightleftharpoons} \mathrm{MR}_{2(\mathrm{sol})}+2 \mathrm{H}_{(\mathrm{aq})}^{+} \text {, }
$$

where HR and $\mathrm{M}^{2+}$ represents the TTA or BFA retained on C18 divalent heavy metal ion, respectively. The subscript "sol" denotes the species on the solid phase C18, "aq" denotes the species in the aqueous phase. The " $K$ " is referred to as distribution constant and can be written as the following equation (2):.

$$
K=\left[\mathrm{MR}_{2}\right]_{(\mathrm{sol})}\left[\mathrm{H}^{+}\right]_{(\mathrm{aq})}^{2} /\left[\mathrm{M}^{2+}\right]_{(\mathrm{aq})}[\mathrm{HR}]_{(\mathrm{sol})}^{2}
$$

The equation (2) is made logarithmic as the following equation (3):

$$
\log K=\log \left[\mathrm{MR}_{2}\right]_{(\mathrm{sol})} /\left[\mathrm{M}^{2+}\right]_{(\mathrm{aq})}+2 \log \left[\mathrm{H}^{+}\right]_{(\mathrm{aq})}-2 \log [\mathrm{HR}]_{(\mathrm{sol})} .
$$

In addition, the distribution coefficients $\left(K_{\mathrm{d}}\right)$ can be calculated as follow:

$K_{\mathrm{d}}=$ moles of metal ion per $1 \mathrm{~g}$ of TTA-C18 or BFA-C $18 /$ moles of metal ion per $1 \mathrm{~cm}^{3}$ of solution.

The equation (4) can be expressed as the following equation (5):

$$
K_{\mathrm{d}}=\left[\mathrm{MR}_{2}\right]_{(\mathrm{sol})} /\left[\mathrm{M}^{2+}\right]_{(\mathrm{aq})}
$$

That is, we can get the following equation (6) from equation (3) and (4).

$$
\log K_{\mathrm{d}}=\log K+2 \mathrm{pH}+2 \log [\mathrm{HR}]_{(\mathrm{sol})}
$$

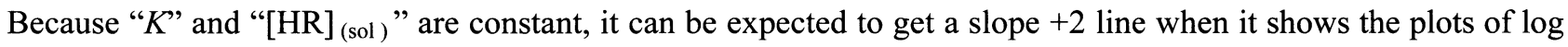
$K_{\mathrm{d}}$ versus $\mathrm{pH}$.

Fig. 2 shows the plots of $\log K_{\mathrm{d}}$ versus $\mathrm{pH}$ of the aqueous solutions. The solid lines in the figure show those with slope +2 . From this result, the reaction in our system can be well expressed by equation (1) for the divalent ions studied. On this reaction, two hydrogen ions were emitted to the aqueous solution when one metal ion, and two TTA and BFA molecules on the $\mathrm{C} 18$ formed a chelate complex. Accordingly, it was concluded that these metal ions were adsorbed on these materials by an ion-exchange reaction. This reaction is a competing reaction between the metal ion and $\mathrm{H}^{+}$expressed with equation (1). Therefore, the results given by this system indicate that the reactivity is high in order of $\mathrm{Cu}^{2+}>\mathrm{Pb}^{2+}>\mathrm{Cd}^{2}$ from an acid side. This order is good agreement with solvent extraction method.[7] Therefore, it is thought that this reaction is

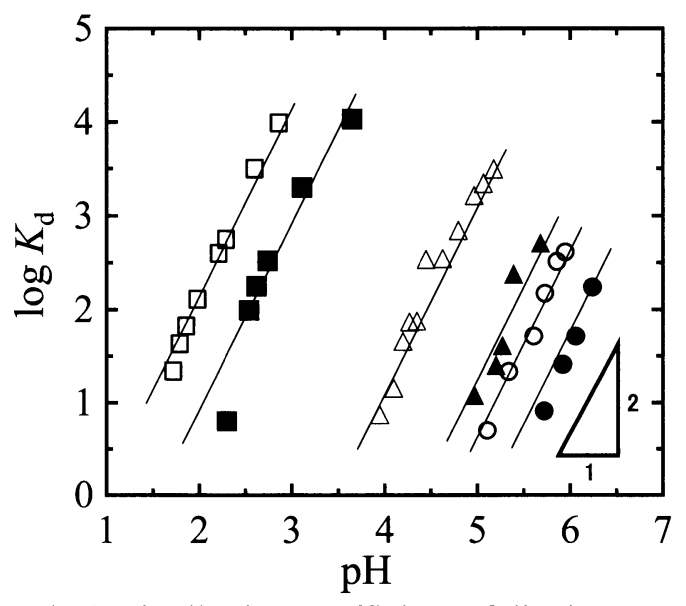

Fig.2 Distribution coefficient of divalent metal ions as a function of $\mathrm{pH}$ with TTA-C18 (closed symbols) and BFA-C18 (open symbols). Square symbols, $\mathrm{Cu}^{2+}$; Circle symbols, $\mathrm{Cd}^{2+}$; Triangle symbols, $\mathrm{Pb}^{2+}$. 
a chelating reaction as well as the solvent extraction system, and the reactivity is decided depending on the stability between metal ion and chelating reagent.[8]

In table 1 , the $\mathrm{pH}$ values of the half-adsorption $\left(\mathrm{pH}_{1 / 2}\right)$ are given for the TTA-C18 and BFA-C18 systems. The "Difference" in table 1 is difference of the $\mathrm{pH}_{1 / 2}$ values between the metal ions, and when the Difference value is greater, it is shown to separate easily by controlling $\mathrm{pH}$ of the aqueous solution containing metal ion. From the table 1, these materials have high mutual separation ability of the metal ions. Using BFA on this system, the metal ions could be adsorbed at high acid range than using TTA-C18 system.

The Difference values of this BFA-C18 system between $\mathrm{Pb}^{2+}-\mathrm{Cd}^{2+}$ was 1.4 although that of the TTA-C18 system was 0.8 . This result shows that BFA-C18 system has better mutual separation ability between $\mathrm{Pb}^{2+}-\mathrm{Cd}^{2+}$ than that of the TTA-C18 system. In contrast, TTA-C18 is excellent in separation between $\mathrm{Cu}^{2+}-\mathrm{Pb}^{2+}$.

It was reported that the $\mathrm{Cd}^{2+}$ can be extracted only less than $50 \%$ by using nitrobenzene with TTA system.[7] Otherwise, in our systems can be adsorbed $\mathrm{Cd}^{2+}$. When the selectivity between $\mathrm{Cu}^{2+}-\mathrm{Pb}^{2+}$ of our system is compared with the solvent extraction system, our system has high separation ability because it is 2.6 in the solvent extraction system while the difference of $\mathrm{pH}_{1 / 2}$ is 2.9 in our system. Thus, it can be said that chelating agent-retained onto $\mathrm{C} 18$ system improved the extraction ability and selectivity than the solvent extraction system.

Table 1 The values of $\mathrm{pH}_{1 / 2}$ and difference between $\mathrm{pH}_{1 / 2}$ of divalent heavy metal ions with TTA-C18 and BFA-C18.

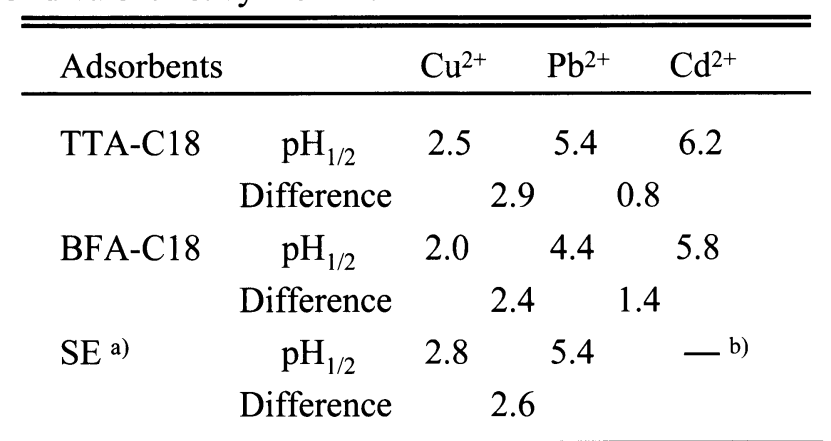

a) SE shows solvent extraction system using nitrobenzene with TTA.[7]

b) Extraction ratio $<50 \%$

Our system achieves the effect of $\beta$-diketone solvent extraction system by using this reported material that retaining $\beta$-diketone on $\mathrm{C} 18$. Moreover, this system has an advantage of a chelating agent that can be used effectively to separate and remove toxic heavy metal ions, such as $\mathrm{Cu}(\mathrm{II}), \mathrm{Cd}(\mathrm{II})$ and $\mathrm{Pb}(\mathrm{II})$, from an aqueous solution without organic solvents. It can be expected in a reduction of the amount of toxic organic solvent used.

\section{References}

1. F. Hagemann, J. Am. Chem. Soc., 72, 768-771 (1950).

2. Y. Komatsu and H. Kokusen, Japan Patent, 3374172 (2001).

3. T. Shimizu, H. Kokusen, S. Tsurubou, M. Sekita, and Y. Komatsu, J. Ion Exch., 14(Suppl)., 369-372 (2003).

4. M. Iiyama, S. Oshima, H. Kokusen, S. Tsurubou and Y. Komatsu, J. Ion Exch., 16, 65-69 (2005).

5. H.Ogawa, T. Koh, K. Taya, and T. Chihara, J. Catal., 148, 493-500 (1994).

6. W.Schöniger, Mikrochim. Acta., 123 (1955).

7. N. Hirayama, M. Deguchi, H. Kawasumi, and T. Honjo, J. Ion Exch.,14 (Suppl.), 345-348 (2003).

8. J. Stary, The Solvent Extraction of Metal Chelates, Pergamon, Oxford, (1964), pp.92-94. 